\title{
Psychodynamic work and older adults
}

\author{
Jane Garner
}

Man can change and go on changing as long as he lives (Horney, 1942)

The congratulations given to people for seeming younger than their years reflects the negative view of old age that permeates our whole culture. Paradoxically, while wanting to live as long as possible few wish to be old and we entertain many stereotypes and prejudices about later life, prejudices that are reflected in the emotional life and mental states of older patients. A psychodynamic perspective emphasises the uniqueness of people and helps their treatment as individuals with their own history, experience, achievements and current situation.

Psychodynamic work makes a number of assumptions: symptoms and personality difficulties have meaning, which is hidden or unconscious; a person has a complex inner world, of which he/she may be unaware but that interacts powerfully with his/her conscious life; a developmental process exists, each stage of which interacts with the person's current state and is with the individual throughout life; the relationship with the therapist is both a diagnostic and a therapeutic tool. If these assumptions are accepted there is no reason why they will not also be applicable to people over the age of 65 . Freud, however, while seeing 'feminine' as the lack of a penis, considered age as the castration of youth and is well-known for his pronouncement about the ineducability of anyone aged over 50 (Freud, 1905). A number of authors have commented on the irony of this comment, made when Freud was 49 , but it is a view that continues to have influence.

Those few analysts who saw and wrote about 'older' patients, for example Karl Abrahams and Elliot Jacques, were treating people in their 30s and 40s. Zivian et al (1992) have shown that therapists prefer to work with younger patients. Old age psychiatrists have tended to concentrate more on physical and social aspects and less attention has been given to the emotional life of patients, with consequent failure to recognise the potential for psychodynamic intervention.

Among those who consider psychodynamic work possible in later life, there are two main schools of thought. One holds that there is a timelessness and persistence to instinctual drives and wishes, which retain their force throughout life, and therefore a reductive approach concentrating on early infantile experience is appropriate. The other view is that the second half of life is different. Jung (1929: p. 38) spoke of a 'psychology of life's morning and a psychology of its afternoon'. With older adults he used a synthetic rather than a reductive approach. In considering the dream of a younger patient he would look at the infantile components of development. With an older patient, however, his interpretations would be more about what could be learned by looking to the future and understanding who the patient is, involving wider issues than childhood experience and relationships with parents. For Jung, the first half of life concerns nature and instincts, the second half culture and spirituality, where the task is selfillumination. The concept of 'individuation' is not about being ill and becoming well but about becoming oneself. Nevertheless, in writing of the archetypes, Jung wrote least about senex: perhaps the prospect of diminishment in old age was disturbing and the adjective 'wise' was added to old man as a defence. Culverwell \& Martin (1999) remind us that to believe wisdom develops merely with the passing of years is just as much an illusion as to believe that people necessarily decline: 'Thou shouldst not have been old before thou hadst been wise', the Fool taunts an ageing King Lear.

While Freud's focus was on reconstructing very early aspects of patients' lives, some later analysts have seen development continuing throughout life. Erikson's epigenetic model using 'eight ages of man' (1966) covers the whole life cycle and is particularly

Jane Garner is a consultant psychiatrist in the Department of Old Age Psychiatry, Chase Farm Hospital (The Ridgeway, Enfield EN2 8JL, UK). She is also a founder member and secretary of the Older Adults Section of the Association for Psychoanalytic Psychotherapy in the National Health Service. 
useful in understanding the elderly condition (Box 1). He supplemented and developed Freud's ideas, which ended in early adulthood. At each stage there are new phase-specific developmental tasks, which have a particular polarity, a contention between opposites. The tasks can either be healthily surmounted and mastered or reacted to in a selfalienating manner. At the same time there is an interaction between current development and early experience. The developmental task in late life is to negotiate between the polarities of ego-integrity and ego-despair. Integrity is the capacity to value one's life experience and oneself 'to be - through having been', holding onto the worthwhile aspects of one's life, memories of having been valued and loved. This is balanced against despair at facing not being and disgust at degeneration. Increasing dependency brings the capacity for trust (the initial task for the infant) once more to the fore. Older people who did not develop basic trust early on may come to the psychiatrist disabled by symptoms of panic and depression, which can be understood as a terrifying fear of dependency (Martindale, 1998).

Object relations theory proposes that human need for connectedness with others is fundamental, irreducible to a drive for food or sex. Attachment theory postulates that we are driven by a need to be in a relationship with others: 'A man's sense of his own identity as a person depends on communication with other persons.' (Storr, 1960: p. 358) All this is true however old we are. The aim of psychotherapy with anyone is to reduce emotional isolation within an intimate and containing relationship. The 'talking cure' involves having someone to listen and to hear.

\section{Common themes}

Basic psychological needs for respect, security and self-determination remain. Hildebrand (1982), drawing on the work of Erikson (1966) and of King (1974, 1980), has listed the particular developmental tasks and difficulties to be negotiated in old age (Box 2). Many navigate these waters with little disturbance but National Health Service (NHS) old age psychiatry services see a number of patients with major difficulties. The exigencies of old age may compel the narcissistic individual to seek help for the first time. Ageing can be viewed as a narcissistic wound from which there is no recovery. Particularly if one is ill and cannot be the cleanest, most hardworking, indispensable and best, one no longer has the buttresses to self-esteem available to younger people. There is a real reduction in older people's ability to influence their external situation, which needs to be acknowledged in therapy.
Box 1 The eight ages of man (Erikson, 1966)

Basic trust $v$. mistrust

Autonomy $v$. shame, doubt

Initiative $v$. guilt

Industry $v$. inferiority (latency)

Identity $v$. role confusion (puberty and adolescence)

Intimacy $v$. isolation (young adulthood)

Generativity $v$. stagnation (adulthood)

Ego integrity $v$. despair

With the prospect and gradual awareness of changes in middle and later life, individuals who have created false-self personalities, able to use professional roles and social position to fulfil narcissistic needs, may seek help. Winnicott (1960) introduced the concept of the true and the false self:

The false self is built upon the basis of compliance. It can have a defensive function, which is the protection of the true self.

Success has been built on identification with external requirements. The false self has adapted itself to socio-environmental pressures and has been treated as if it were real. However, the patient often has an inkling of futility, alienation and despair that increases and threatens to overwhelm as the external environment changes, for example on retirement.

In some, dependency and fear of dependency are in conscious minds and mental states. In others, the fear emerges during psychological work. Psychiatric staff may use the description 'dependent' as a criticism and a reason to discharge the patient.

Box 2 Developmental tasks and difficulties in later life (Hildebrand, 1982)

Fear of diminution/loss of sexual potency

Threat of redundancy in work roles; being replaced by younger people

The need to reconsider and perhaps remake the marital relationship after children have left

Awareness of one's own ageing, illness and possible dependence

Awareness that what one can achieve now is limited

The feeling of having failed as a parent (paradoxically exacerbated in the childless)

Loss of a partner and of intimacy

The fact of one's own death in terms of narcissistic loss and pain 
However, with increasing frailty in later life, being able to accept help is a strength. Martindale (1989) describes the fears of dependency in both elderly patients and their younger therapists, the latter feeling trapped and fearing a very lengthy relationship. How people deal with dependency in later life reflects how dependency issues were negotiated early in life, whether the carer is seen as 'good enough', whether anxieties about 'will they hate me?', 'will they be disgusted by me?' threaten to overwhelm the older person.

Losses occur at any time, but with ageing they multiply and accumulate. Porter (1996) quotes from Hamlet, 'When sorrows come, they come not single spies, but in battalions'. Changing physical characteristics and sexuality can be losses just as devastating as losses of financial status, work and role; friends and partner; independence and home; and health and mobility. There is also the terror of anticipated loss, including life itself and the possibilities of all those things one has not had and not done but to which at a younger age one could still aspire. For Pollack (1982) mourning-liberation is the focus for work with older patients. Liberation from mourning allows the past to be just that and opens up new possibilities in relationships and activities and a view of death that may include completion and freedom. Successful ageing derives from the ability to mourn for the self.

There are a number of different psychological views of death, perhaps reflecting differences between people, both clinicians and patients. For Knight (1986) the task of negotiating death is one for middle life, so that older people have often come to terms with their own mortality. However, Segal (1958) reported the successful analysis of a 73-year-old man in whom the unconscious fear of dying, which increased with age, had led to a psychotic breakdown. Death here was viewed as a persecutory or depressive anxiety. Other writers, for example Martindale (1998), conceive of the unconscious as timeless, seeing an eternity for itself so that death is not a possibility. There is no unconscious recognition of 'not being' or nothingness. However, there are numerous worries about how to live nearing physical death: how one will deal with increasing dependency, pain and physical disintegration. The patient's anticipated 'life after death' may be of clinical significance. Individuals may develop the illusion that the staff who care for them, or at least the institution in which they are patients, is eternal. This needs to be remembered when discharging or transferring people. The patient who knows he/she can come back may not have need to; a reluctance to end may unconsciously be linked to the fear of death. There may be a reawakening of early trauma if the realisation of mortality rekindles early fears of abandonment. Most of us work in a Western culture that constructs individual destinies. There is a Christian investment in the body, which is tormented, killed and is finally reborn, overcoming death. Other cultural and religious traditions invest less in the body and in death: current experience is transitory, death may be a release to the nirvana of undifferentiation. Clinical views need to be linked to cultural concepts in this and other respects.

The phrase 'growing old' suggests there may be positive aspects, although growth is not necessarily a linear progression. Perhaps older people should be credited with greater ego-strength - they bring into old age all the positive attributes and coping skills that have helped them previously; they have an increased capacity for delayed gratification and for getting on with things. Ardern et al (1998) note that although some patients need to know that staff will be available to them 'for ever', for others a knowledge of their own brief remaining time accelerates psychological change and adaptations. Creativity and old age are not strangers and it is possible to think of many artists, musicians, actors, theoreticians and analysts who have produced work of the highest standard with advancing years. Many people use the additional time available after retirement to extend their knowledge and develop their talents. However, perhaps ageing itself is, for those with sufficient internal resources, a creative process. It is a time of new experiences, and even negative experiences may offer lessons for strengthening one's internal world. Salzberger-Whittenberg (1970) has written:

Some losses are an inevitable part of our life experience and are indeed necessary for the attainment of mature adulthood. For the work of mourning can lead to a greater integration, strengthening of character, the development of courage, and to deeper concern for others as we come to appreciate the preciousness of others' and our own time of life (p. 112).

\section{Countertransference}

Working with patients who are older, possibly much older, who perhaps have intractable physical problems or a dementing illness, evokes particular feelings in staff, who may see the patient as a grandparent, parent or themselves in old age. Unhelpful sentiments of pity may emerge or sadism stimulated by an ostensibly unequal power relationship. Conversely, it is possible to idealise the older patient as the wished-for parent or grandparent. The dependent patient may be feared and rejected. The patient's feelings of helplessness projected onto the therapist may leave him or her feeling impotent or paralysed. 
Unthinking staff may stimulate in older patients an envy of youth and of a young sexuality; some may even enjoy seeing themselves in this apparently positive way, but others may need to deal with the guilt they feel at simply being younger. Doctors can have difficulties working with older people, the treatment of life in decline may be a wound to our medical narcissism and magic expectations. We may adopt an attitude of therapeutic nihilism or, conversely, embark on heroic treatments that cause pain and distress to all concerned.

Issues related to changes in sexuality may be pressing for the patient and ignored by the therapist who finds it easier to think of old age as lacking sexuality - perhaps owing to the therapist's Oedipal reactions to parents. Some old people who entertained these opinions earlier in life oblige by themselves taking a negative view of sexuality in advancing years, thus perpetuating the stereotype.

As with any psychological intervention, good supervision is essential, particularly as an aid to understanding the powerful feelings evoked by working with this patient group.

\section{Groups}

Ong et al (1987) has demonstrated the value of a support group after discharge for patients hospitalised for depression. Others have successfully used a group analytic approach to treatment and to reducing emotional isolation. The same themes and transference reactions emerge as in individual therapy, but in addition the major issues of ageing are presented concretely by fellow group members. The frequently cited reason older people give for not joining in activities or clubs - that they are full of old people - can be fully explored. Patients are not unaware of society's prejudice and stereotyping, which they share and project onto others in the group (Evans, 1998). In therapy they can be helped to take these projections back and see themselves and others as whole people, not only as 'old'.

\section{Families, couples and carers}

Most work with families where the referred patient is elderly has used a systemic model. Increasing attention is being paid to elderly couples but few therapists use a psychodynamic approach. Work with carers has for the most part used a stressburden perspective, with interventions aimed at reducing the burden of care. Although often successful, this can fail badly if unconscious conflicts stimulated by the role of caring are not also taken into account (for further discussion of this point, clinical examples and ways in which provision of psychotherapeutic support for carers may be beneficial see O'Connor (1993) and Garner (1997)).

The loss of a partner to dementia can be extremely painful. Some workers have described this as anticipatory grief, others write of partial losses. What is really lost and being grieved is mutuality and reciprocity in the relationship. The person with dementia is no longer a confidant(e): 'He's not the man I married, doctor'. The manifestation of any grief reaction is always influenced by previous experience of loss and intrapsychic factors - ego strength and development, unconscious hostility, ambivalence and identification with the introjected patient into the self - all these contribute to individual variation in the grief response. As in post-death grief reactions, one of the main influences on the grief associated with dementia in a partner is the quality of the premorbid relationship. Staff working in this area need to be able to organise practical help and services while at the same time having a psychotherapeutic understanding of the issues involved. This will enable them to help the carer look at the meaning of the disease, its symptoms and its losses, to allow an acknowledgement and working through of the sense of loss, anger and grief.

\section{Dementia}

Of all the losses of later life the most desperate and difficult for some is the loss of the self to dementia. The epidemiology of dementia is such that it is just at the time the individual is negotiating between the polarities of ego integrity and ego despair (Erikson, 1966) that actual disintegration of the self and identity is most likely to occur. Health professionals tend to divide conditions in a Cartesian way into mind (psychogenic) and brain (organic). We are interested in offering psychological interventions for the former not the latter. However, all conditions must be a summation of both. In dementia, real organic loss shares an existence with temporary emotionally caused impairment. Sinason (1992) has written a moving account of psychotherapy with an academic who had to retire because he had developed Alzheimer's disease. Her work with patients with learning disability has made us think about the word 'stupid', which the Oxford English Dictionary defines as 'numbed or stunned with grief, stupefied'. The majority of interventions for patients with dementia tend to be for those around the sufferer 
or to be pharmacological, social or behavioural. A psychodynamic approach adds an emotional dimension and helps staff to see the patient as an individual with a unique history and experience. Sometimes, patients with dementia are for the most part mute but they become coherent, even grammatical, when furious. In the same way, a therapeutic understanding that emotionally reaches the patient may integrate the memory, albeit for the moment.

This work is not easy and is fraught with obstacles (Hausman, 1992), some brought by the therapist, who needs to tolerate and understand feelings of hostility, helplessness, frustration and nihilism that can be stimulated by working with a patient with irreversible illness. The therapist needs to be more flexible in terms of the number and length of sessions (15 minutes three times a week may be better than 50 minutes once a week), informality and use of props such as photographs or favourite objects. It must be remembered that the therapy is not to get the patient to work in a cognitive mode that he/she has lost but for him/her to be understood as he/she is. Not all skills deteriorate at the same rate and there are aspects of dementia that are positive for this type of work: patients are able to form relationships until very late in the disease; there seems a hunger for empathic human contact, so that relationships develop quickly; an emotional life is not dependent on language and patients can be reached affectively long after they cease to be reached cognitively; recognition skills are retained after the ability to recall is lost.

It is unlikely that many patients with dementia will be taken on for this type of work. However, it would be educational and helpful for staff in old age psychiatry to see such a patient under supervision, so that understandings acquired may be used to instruct general psychiatric work with this group of patients.

\section{Staff support and service development}

The concept of the 'cradle to grave' welfare state has not withstood the politico-economic onslaught of the past two decades, and the increase in the number of people aged over 75 has been paralleled by a decrease in public sector provision. The generation subject to ration books during the Second World War is now subject to rationing in the NHS (Davenhill, 1998). Some authors (Evans, 1998) have taken up the notion of malignant mirroring (Zinkin, 1983) to explain the poor services expected by and provided to older people - what is offered to someone actually reflects his/her psychopathology. Few older

\section{Box 3 Psychotherapeutic capacities}

To listen and empathise with the patient and to make some sense of his or her experience using personal emotional response as a source of understanding

To contain anxiety and despair, rather than always feeling compelled to act

To bear hostility and criticism without retaliation

To identify a distorted perception in the staffpatient relationship

patients are referred or taken on for psychodynamic psychotherapy. However, the principles and understanding derived from the theory and practice of this type of psychotherapy may be used to inform the service as a whole (Ardern et al, 1998) in the same way as has been demonstrated in some general psychiatry units. It is demanding and stressful to work with physically and mentally dependent older people and with their families, who may project guilt and hostility. Staff need support and training to prevent them feeling either overwhelmed or detached, to help them understand and not act out the potential for abuse and to enable them to discuss openly the feelings this type of work evokes. Psychiatric staff already possess psychotherapeutic capacities (Box 3), and these could be strengthened by supervision of their day-to-day work by a psychotherapist (Temple, 1999).

Porter (1996) has described the use that can be made of a psychoanalytic psychotherapist by an old age psychiatry team. Additional skills are brought to complement other biological, social and psychological approaches. Older people carry additional burdens in all three of these areas, but we are less adept at addressing the psychological and usually find it easier to prescribe medication or organise a day centre. Both may be useful, but if that is all we do we may fail to address major issues for our patients. The 'impossible patient' is showing us what it is like to be in his/her impossible situation. Perhaps he/she rages as a consequence of despair and powerlessness.

It often happens that patients are referred to old age psychiatry services with no psychiatric diagnosis or even symptoms but because of difficulties they pose to other professionals attempting to help. The following brief vignette is not untypical.

\section{Case vignette}

Mr B. was referred in the same week by both his general practitioner (GP) and social services, with whom he was in dispute. He was a retired, previously self-employed businessman, a widower, living alone in a large, now dilapidated, house. Increased frailty 
due to arthritis and some cardiac failure prevented him from caring for himself adequately or getting to the shops. Neighbours had tried to assist him but had been rebuffed and social services had been summarily dismissed. He was visited by two members of the team, a doctor and a community psychiatric nurse. It was difficult to persuade him to let the staff into his home to speak with him, although being 'sent' by the GP and therefore being in some supposed hierarchy helped a little. He was scathing that the doctor was female, as 'women know nothing', but he did acknowledge that at least she seemed reliable, having turned up at the time she had arranged.

Photographs in the house were of a good-looking, physically powerful man, a contrast to the unshaven, shambling, tramp-like figure he had become. In his history he described a materially impoverished childhood; a beautiful mother whom he adored and despised in equal measure; an energetic, decisive father whom he admired and with whom he was identified, who died in old age 2 years after being seriously disabled by a stroke. He was not clinically depressed but communicated a sense of fury and of desperation. He seemed to feel a terror of diminishment and of castration (in the broadest sense). He feared being 'put in a home', which was the solution proposed by his estranged daughter.

There was no 'solution' but what helped was seeing $\mathrm{Mr}$ B. over a few weeks and showing an understanding that in his current position he felt powerless, greatly at odds with his previous experience of being a 'self-made man' used to making decisions and having others (including his wife) act on them, and acknowledging his fear of becoming as dependent as his father was in later years. With encouragement he was able to negotiate with social services and to make decisions about his care, for example having a male domiciliary care assistant and deciding how often and when he should visit. He was also able to accept the GP's prescription of an analgesic. Mr B. did not have formal psychotherapy but time was spent with him and efforts were made to understand his problems (which are common in older people) and to help him to cope with them practically and emotionally.

\section{Outcome}

It may be easier to see change in younger people, as changes in external reality are more likely to occur in parallel with internal change. Culverwell \& Martin (1999) suggest that working with older people requires a refocusing of the idea of therapeutic change. This may be particularly true bearing in mind the disabilities of the patients who come to NHS services. Our goals may be to encourage acceptance of loss and limitations, to prevent deterioration or to reduce the disruption of distressing life changes.
While older people are less likely to be referred for psychological interventions, perhaps because role expectation is low, there is no evidence that these treatments are less effective in an older age group. Looking only at randomised control trials and thereby missing the information that can usefully be gained from open trials and single case reports, Woods \& Roth (1996) noted a positive outcome for structured psychodynamic psychotherapy for depression. Knight (1996) writes that psychodynamic therapy has a long history of case studies reporting success with older clients and that these have been confirmed by randomised clinical outcome studies. Indirect parameters such as staff turnover or incidents of abuse (Royal College of Psychiatrists, 2001) may provide a useful outcome measure in terms of quality of service delivery and the benefit of using the skills of a psychoanalytic psychotherapist.

\section{Strategic review of psychotherapy services in England}

The NHS Executive's strategic review of psychotherapy services in England emphasised the need for accessibility and equity across patient groups (NHS Executive, 1996). Psychological treatments need to be available as an integral component of mental health care. Older patients often fall into the category of those with 'severe and enduring mental illness', who require a multi-faceted and multidisciplinary approach to care. With a view to costeffectiveness, the review put some emphasis on brief therapies - 10 weekly sessions - but also correctly mentioned that treatments are cost-ineffective if they are too short to deliver a therapeutic effect. Clinical experience with older patients in the NHS suggests that different structures and paradigms may be more appropriate with this age group. Patients may need to be seen over a longer period of time but for less frequent sessions. The document is clear that 'services appropriate to older adults should be available'. Clinicians and health authorities should bear this in mind when planning services and setting quality standards.

\section{Conclusion}

Aristotle used the word engeria to denote a long and happy life without suffering or being a burden to others. How to age well has been of interest over the 
centuries. The youth-centred hegemony of the past 50 years has turned this into a preoccupation with remaining and seeming young for as long as possible. Professionals and services have followed with a relative neglect of older people; even when biological and social needs have been catered for emotional ones remain unacknowledged. The psychodynamic model is important in that it places particular emphasis on the uniqueness of people and their experience and it is able to address the fears of staff working with this patient group. Increasing psychotherapeutic skills is a way of developing and enhancing communication with patients regardless of their diagnosis or age.

\section{References}

Ardern, M., Garner, J. \& Porter, R. (1998) Curious bedfellows: psychoanalytic understanding and old age psychiatry. Psychoanalytic Psychotherapy, 12, 47-56.

Culverwell, A. \& Martin, C. (1999) Psychotherapy with older adults. Older People and their Needs (ed. G. Croley). London: Whurr.

Davenhill, R. (1998) No truce with the furies. Journal of Social Work Practice, 12, 149-157.

Erikson, E. (1966) Eight ages of man. International Journal of Psychoanalysis, 47, 281-300.

Evans, S. (1998) Beyond the mirror: a group analytic exploration of late life and depression. Ageing and Mental Health, 2, 94-99.

Freud, S. (1905) On psychotherapy. Reprinted (1953-1974) in the Standard Edition of the Complete Psychological Works of Sigmund Freud (trans. and ed. J. Strachey), vol. 7, pp. 257-268. London: Hogarth Press.

Garner, J. (1997) Dementia: an intimate death. British Journal of Medical Psychology, 70, 177-184.

Hausman, C. (1992) Psychodynamic psychotherapy with elderly demented patients. Care Giving in Dementia (eds M. M. Jones \& B. M. L. Meisen), pp. 181-198. London: Routledge.

Hildebrand, H. P. (1982) Psychotherapy with older patients. British Journal of Medical Psychology, 55, 19-28.

Horney, K. (1942) Neurosis and Human Growth. New York: WW Norton.

Jung, C. G. (1929) Aims of psychotherapy. Collected Works, vol. 16, p. 38. London: Routledge and Kegan Paul.

King, P. H. M. (1974) Notes on the psychoanalysis of older patients. Journal of Analytical Psychology, 19, 22-37.

- (1980) The life cycle as indicated by the nature of the transference in the psychoanalysis of the middle aged and elderly. International Journal of Psychoanalysis, 61, 153-160.

Knight, B. (1986) Psychotherapy with Older Adults. Thousand Oaks, CA: Sage.

Knight, B. G. (1996) Psychodynamic therapy with older adults: lessons from scientific gerontology. Handbook of the Clinical Psychology of Ageing (ed. R. T. Woods), pp. 545-573. Chichester: John Wiley \& Sons.

Martindale, B. (1989) Becoming dependent again: the fears of some elderly persons and their younger therapists. Psychoanalytic Psychotherapy, 4, 67-75.

- (1998) On ageing, dying, death and eternal life. Psychoanalytic Psychotherapy, 12, 259-270.

NHS Executive (1996) NHS Psychotherapy Services in England: Review of Strategic Policy. Leeds: NHS Executive.

O'Connor, D. (1993) The impact of dementia: a self psychological perspective. Journal of Gerontological Social Work, 20, 113-128.
Ong, Y. L, Martineau, F., Lloyd, C., et al (1987) A support group for the depressed elderly. International Journal of Geriatric Psychiatry, 2, 119-123.

Pollack, G. (1982) On ageing and psychotherapy. International Journal of Psychoanalysis, 63, 275-281.

Porter, R. (1996) The psychoanalytic psychotherapist and the old age psychiatry team. Psychiatry in the Elderly (2nd edn) (eds R. Jacoby \& C. Oppenheimer), pp. 257-268. Oxford: Oxford University Press.

Royal College of Psychiatrists (2001) Institutional Abuse of Older Adults. Council Report CR84. London: Royal College of Psychiatrists.

Salzberger-Whittenberg, I. (1970) Psychoanalytic Insight and Relationships: A Kleinian Approach. London: Routledge and Kegan Paul.

Segal, H. (1958) Fear of death: notes on the analysis of an old man. International Journal of Psychoanalysis, 39, 173181.

Sinason, V. (1992) Mental Handicap and the Human Condition. New Approaches from the Tavistock. London: Free Association Books.

Storr, A. (1960) Torture without violence. New Statesman, 12 March, p. 358

Temple, N. (1999) Should consultant psychiatrists be trained in psychotherapy? Advances in Psychiatric Treatment, 5, 288295.

Winnicott, D. W. (1960) Egodistortion in terms of true and false self. In The Maturational Processes and the Facilitating Environment. London: Hogarth.

Woods, R. T \& Roth, A. D. (1996) Effectiveness of psychological interventions with older people. Psychotherapy: What Works for Whom (eds Roth A. D. \& P. Fonagy). New York: Guildford Press.

Zinkin, L. (1983) Malignant mirroring. Group Analysis, XVI, 113-126.

Zivian, M. T, Larsen, W., Knox, V. J., et al (1992) Psychotherapy for the elderly: psychotherapists preferences. Psychotherapy, 29, 668-674.

\section{Multiple choice questions}

1. With regards to ageing:

a people necessarily develop wisdom with age

$b$ old people are able to influence their environment as much as younger people can

c ageing may be particularly difficult for individuals with narcissistic personality structure

d if older patients show signs of becoming dependent on the clinic/hospital, they should be discharged

e sexuality is not an issue after 65 years of age.

2. In psychodynamic theory:

a the unconscious is ageless

$\mathrm{b}$ external reality is ignored

c experiences only up to the age of 5 are considered important

$\mathrm{d}$ the unconscious interacts with conscious life

e an understanding of staff reactions to a patient may elucidate some of the patient's problems. 
3. Regarding psychodynamic work:

a this is contraindicated if the patient has a diagnosis of dementia

b patients in later years may make positive changes more quickly

c it is not appropriate for patients taking psychotropic medication

$d$ it is useful only when considering the treatment of particular patients individually

e there may be a tension between a patient's current developmental stage and a revival of early experience.

4. The psychotherapeutic capacities of psychiatric staff:

a are useful only within a therapy session

$\mathrm{b}$ preclude action

c include the capacity to contain anxiety

d may be achieved only through personal analysis

e include the ability to retaliate.
5. Regarding psychodynamic work:

a there is no evidence that this type of work is less effective with older than with younger patients

b the patient is always aware of his or her inner world

c the transference relationship is a diagnostic tool

d negative feelings about patients should not be shared in supervision

e few older patients are referred for psychodynamic psychotherapy.

\section{MCQ answers}

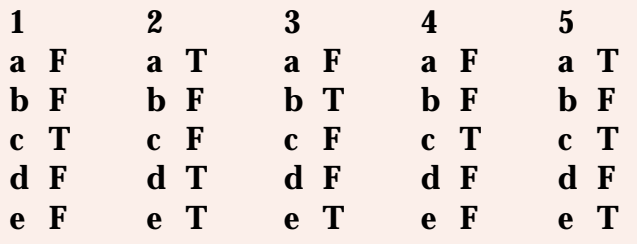

\title{
Commentary
}

\author{
Mark Ardern
}

Not so long ago I attended a conference with colleagues in old age psychiatry. Shortly before lunch the Chairman of the morning session stood up, ostensibly to praise the preceding speaker for his lecture. His words went something like: 'Thank you Dr X. I'm sure we'd agree that your excellent talk has given us all thought for food.'

Such startling betrayals of the unconscious are, of course, rare. Freudian analysis of dreams is also an uncommon pastime in our everyday clinical practice. Nevertheless, in old age psychiatry evidence for unconscious activity is to be found, for example, in psychotic processes, in the fragmented behaviour of people with dementia and in interactions between patients and staff.
Old age psychiatrists are drawn into all aspects of ageing. A detailed consideration of each patient's predicament requires time. Garner (2002, this issue) argues that psychodynamic work is time well spent, particularly when it acknowledges the multiplicity of our practice. Hardly any patients of mine will be suited to 50-minute sessions on a psychoanalytic couch. Many cannot see or hear properly; others do not know who we or their loved ones are. Few will ask for psychological treatments of any sort. And yet, all of our patients are searching for something, usually in the form of a relationship. We therefore have to adapt psychoanalysis to fit the modern world and the old people who inhabit it.

Mark Ardern is a consultant psychiatrist for the elderly at St Charles Hospital (Exmoor Street, London W10 6DZ, UK). He is also Chairman of the Older Adults Section of the Association for Psychoanalytical Psychotherapy in the NHS. 